\title{
La teoría de sistemas en desarrollo como operación dialéctica ${ }^{*}$
}

\author{
Developmental Systems Theory as a Dialectic Operation
}

Julio Muñoz Rubio ${ }^{\dagger \ddagger}$

\begin{abstract}
Resumen
El concepto marxiano de fetichismo de la mercancía es susceptible de aplicación en biología evolutiva para revelar muchas imprecisiones contenidas en las concepciones neodarwinistas y parte de su carácter ideológico. Postulo que el Dogma Central de la Biología Molecular es una expresión de la fetichización de procesos complejos que requieren la concurrencia de múltiples variables y entidades, que no siempre pueden ser explicados a partir de la presencia de los ácidos nucleicos. El presente trabajo lleva tres niveles de análisis: por una parte en el método dialéctico hegelianomarxista, por otra en las tesis de Karl Marx, e Ivan Rubin acerca del fetichismo de la mercancía y finalmente en la obra de evolucionistas como S. Oyama, Richard Lewontin y Richard Levins. Pongo especial énfasis en la Teoría de Sistemas en Desarrollo, postulada por Oyama, afirmando que es una innovadora concepción que devela fetichismos y mistificaciones del neodarwinismo.
\end{abstract}

Palabras clave: dialéctica - fetichismo - marxismo - reduccionismo - teoría de sistemas en desarrollo

\begin{abstract}
The Marxian concept of Commodity Fetishism can be applied on evolutionary biology to expose inaccuracies of NeoDarwinist conceptions and their ideological nature. I postulate that the Central Dogma of Molecular Biology is an expression of the fetishization of complex processes that require the concurrence of multiple variables and entities. The present work has 3 levels of analysis: first, the Hegelian-Marxist dialectical method; second, the Karl Marx and Ivan Rubin thesis on fetishism of commodities; and finally, the work of evolutionists such as Susan Oyama, Richard Lewontin, and Richard Levins. I argue that the Developmental Systems Theory, proposed by Oyama, is an innovative conception that reveals fetishisms and mystifications of Neo-Darwinism.
\end{abstract}

Keywords: dialectics - fetishism - marxism - reductionism - developmental systems theory

* Recibido: 10 de Junio de 2014. Aceptado en versión revisada: 15 de Agosto de 2014.

† Centro de Investigaciones Interdisciplinarias en Ciencias y Humanidades, UNAM, México. Para contactar al autor, por favor, escribir a: juliomunozr2000@yahoo.es.

* El presente trabajo forma parte del Proyecto PAPIIT IN 402013, financiado por la Dirección General de Asuntos del Personal Académico (DGAPA) de la Universidad Nacional Autónoma de México (UNAM), México, a quien se agradece su apoyo.

Metatheoria 5(1)(2014): 99-112. ISSN 1853-2322.

(C) Editorial de la Universidad Nacional de Tres de Febrero. Publicado en la República Argentina. 


\section{El Fetichismo marxiano, su pertinencia en la biología}

La ciencia, natural y social, ha sido presentada, en su forma hegemónica, como un conjunto de parcelas de conocimiento, con vínculos más o menos ocasionales, pero fundamentalmente, como campos separados tanto ontológica como epistemológicamente. Esto ha tenido consecuencias negativas para comprender los fenómenos bajo estudio desde la totalidad de las integraciones que se presentan. La realidad se exhibe de manera inconexa y parcial, y eso, que ya en sí es una forma ideológica (falsa conciencia) de concebirla, reproduce la ideología en muchas de las teorías que se postulan, y en las prácticas y debates a los que dan lugar.

En este trabajo adopto la concepción marxista del término ideología, que describe el proceso de imposición que el sujeto cognoscente tiene acerca de la realidad, por encima de la realidad misma. Mediante ese proceso, se lleva a cabo una inversión inconsciente de la relación objeto-sujeto en el proceso del conocimiento. Una de las consecuencias de que el sujeto considere equivocadamente que su idea de la realidad es la realidad misma, es que se produce una desvinculación de él mismo con respecto del objeto que estudia y la metodología que emplea, y todo ello con respecto al proceso histórico que les ha dado lugar; los abstrae de su contexto global y el conocimiento obtenido queda sesgado a una visión superficial: a la admisión de las leyes de la realidad inmediata como si fueran leyes universales (Engels [1893]1997, p. 95, Marx \& Engels [1845]1953). ${ }^{1}$

\subsection{Ideología, ciencia y neodarwinismo}

La discusión acerca del carácter de las relaciones entre ciencia e ideología se refiere a cómo es que la ciencia muestra frecuentemente imágenes distorsionadas del mundo, inadecuaciones entre la esfera del pensamiento y la realidad externa.

El neodarwinismo es un caso claro de tesis científicas con sesgos ideológicos. A pesar de contener un sólido cuerpo de conocimientos validados a lo largo de décadas de investigación, es, al mismo tiempo, víctima de postulados ideologizados que, en tanto tales, llevan a la descontextualización y eternización de las categorías analíticas y de los procesos que ellas señalan. Con esto, el neodarwinismo ha llevado a la fetichización de ciertos procesos y categorías centrales de su propuesta.

Aplico aquí el concepto marxiano de fetichismo. Karl Marx lo concibe como un proceso psicosocial en el cual un objeto se muestra dotado de poderes o características misteriosas que parecen hacerlo prescindible de toda relación; como algo cuya existencia en el universo fuera resultado de sí mismo. El fetiche sirve como un velo que oculta la totalidad de las relaciones espacio-temporales que lo explican, y con ello su origen, su devenir, su historia. Esto es una impresión introyectada en las mentes de los sujetos que se relacionan con el objeto fetichizado. Lo grave de tal proceso es que se pierde la conciencia de ese carácter fetichista y se toma al fetiche como algo que verdaderamente posee esas propiedades mágicas, con lo cual la realidad resulta afectada y deformada.

Marx resalta las consecuencias psicológicas de la existencia humana en el mundo capitalista, donde toda relación de trabajo conduce a la producción de valor de cambio. Si bien desde la revolución neolítica aparece este último, es en el capitalismo cuando su producción es ya universal. En esa medida, todas las relaciones sociales se convierten en relaciones de mercado o en reflejos y reproducciones de ésta. El fetichismo alcanza niveles que en ninguna época de la historia se había alcanzado. Así se explica que para Marx hayan sido objeto de atención central las misteriosas propiedades de la mercancía. Señaló en ese sentido que:

Lo misterioso de la forma mercantil consiste sencillamente, pues, en que la misma refleja ante los hombres el carácter social de su propio trabajo, como caracteres objetivos inherentes a los productos del trabajo y como propiedades sociales naturales de dichas cosas, y por ende, en que también refleja la relación social que media entre los productores y el trabajo global, como una relación social entre los objetos, existente al margen de los productores (Marx [1867]1988, p. 88).

\footnotetext{
${ }^{1}$ Excelentes compilaciones sobre el concepto de ideología son: Lenk (2000), Eagleton (1996) y Zizek (2003).
} 
Lo que aquí adopta, para los hombres, la forma fantasmagórica de una relación entre cosas, es sólo la relación social determinada existente entre aquellos. De ahí que para hallar una analogía pertinente debamos buscar amparo en las neblinosas comarcas del mundo religioso. En éste los productos de la mente humana parecen figuras autónomas dotadas de vida propia [...]. Otro tanto ocurre en el mundo de las mercancías con los productos de la mano humana. A esto llamo el fetichismo que se adhiere a los productos del trabajo no bien se los produce como mercancías (Marx [1867]1988, p. 89).

A estos [los productores], por ende, las relaciones sociales entre sus trabajos privados se les ponen de manifiesto [...] no como relaciones directamente sociales trabadas entre las personas mismas, en sus trabajos, sino por el contrario, como relaciones propias de cosas entre las personas y relaciones sociales entre las cosas (Marx [1867]1988, p 89).

Por esto decimos que el fetichismo es una falsa conciencia del mundo, es decir, es una manera de imponer al sujeto ideas del mundo como si fueran fiel expresión de la realidad misma. Marx añade:

Las formas que ponen la impronta de mercancías a los productos del trabajo y por tanto están presupuestas a la circulación de mercancías, poseen ya la fijeza propia de formas naturales de vida social, antes de que los hombres procuren dilucidar no el carácter histórico de esas formas -que más bien, ya cuentan para ellos como algo inmutable- sino su contenido [...]. Pero es precisamente esa forma acabada del mundo de las mercancías la que vela de hecho, en vez de revelar, el carácter social de los trabajos privados, y por tanto las relaciones sociales entre los trabajadores individuales (Marx [1867]1988, pp. 92 93).

Marx señala cómo lo que debe ser analizado como proceso, como devenir y como historia, es tomado en una forma fija, inmutable y eterna. Lo que es un producto de la historia es tomado como ley natural, lo que es una parte de la realidad, transitoria, es tomado como toda una realidad incambiable y fija. Todo esto es también el fundamento de lo ideológico.

Este proceso inconsciente lleva a considerar, a "las características de las cosas, como características naturales que pertenecen a las cosas mismas" (Rubin 1974, p. 75). De este modo resultados de las relaciones sociales, tales como valor o dinero "no son considerados como expresiones de relaciones humanas 'vinculadas' a las cosas, sino como características directas de las cosas mismas" (Rubin 1974, p. 75). Rubin añade que no es el valor de las cosas lo que las caracteriza, sino las relaciones humanas específicas en el contexto de producción de cosas, las que le atribuyen su valor. Éste no es una "propiedad de las cosas", sino "una forma social que adquieren las cosas por el hecho de que las personas entran en determinadas relaciones de producción a través de las cosas." Es decir, el fetichismo, que confiere a las cosas propiedades desligadas de las relaciones que las producen, invierte la relación entre sujeto y objeto, haciendo parecer que el sujeto sería en realidad un objeto pasivo que moldea objetos a voluntad de éstos, sometiéndose y dirigiéndose a ellos como si fueran los que produjeran a los individuos.

Marx añade otros elementos a su análisis del carácter ilusorio y fantasmagórico de la mercancía, observando cómo el dinero parece producirse por sí sólo en la esfera del interés y el crédito:

En el capital que devenga interés, la relación de capital alcanza su forma más enajenada y fetichista. Tenemos aquí D-D', dinero que genera más dinero, valor que se valoriza a sí mismo, sin el proceso que media ambos extremos [D-M-D'] (Marx [1894]1985, p. 499).

D-D'; aquí tenemos el punto de partida originario del capital, el dinero en la fórmula D-M-D' reducido a sus dos extremos $D_{-} D^{\prime}$ siendo $D^{\prime}=D+\Delta D$, dinero que crea más dinero. Es la forma originaria del capital reducida a un compendio carente de sentido [...]. El capital aparece como la fuente misteriosa y autogeneradora del interés, de su propia multiplicación. La cosa (dinero, mercancía, valor) ya es capital como mera cosa; el resultado del proceso total de reproducción aparece como un atributo que recae de por sí en una cosa (Marx [1894]1985, p. 500).

Es decir, estamos aquí frente a una forma extrema de fetichismo. En donde la cosa-dinero, como mercancía cuyo valor de uso es el de servir de valor de cambio universal, es sustraída al conjunto de sus relaciones sociales y su historia para presentarse como una cosa que mágicamente parece reproducirse a sí misma. Parece así que la mercancía produce sobre la mente humana la impresión de ser algo imprescindible para el conjunto del funcionamiento social. 
El fenómeno fetichista no se limita al de la mercancía, se extiende a muchas otras esferas de la realidad: El fetichismo del Estado, de las relaciones afectivas, el religioso, el de las formas de pensamiento. En todos estos casos el objeto, sujeto, proceso, concepto o institución fetichizada es un producto humano, que no bien ha sido producido parece adquirir una vida propia, ajena a la de los humanos que la produjeron.

En ciencia moderna el concepto de partícula esencial es uno de los mejores ejemplos de fetichismo. Es en los sistemas reduccionistas de filósofos como René Descartes donde adquiere relevancia y proyección. Descartes asevera que la verdad en el conocimiento del mundo sólo puede determinarse dividiendo cada sistema de estudio hasta encontrar una partícula última y esencial, la cual puede entenderse por sí misma, en ausencia de relaciones. Así, afirma que "Cuando concebimos la sustancia, solamente concebimos una cosa que existe en forma tal que no tiene necesidad sino de sí misma para existir" (Descartes 1995, parte primera, aforismo 51). En tesis como esta se observa la característica del fetiche: Autosuficiencia e imprescindibilidad. Para Descartes, el universo físico se compone de partículas cuyas propiedades se pretenden fijas e inmutables y son expresadas en y por los demás componentes del sistema bajo estudio. La propiedad esencial se transmite a todas ellas desde esa partícula última, que subsiste por sí sola.

Con tesis como las citadas, la ciencia natural naciente de tiempos de Descartes, comienza a elaborar sus leyes partiendo de la existencia de sus categorías de análisis fundamentales, pero sin comprenderlas históricamente. Esta característica será compartida, con el transcurso del tiempo, por la ciencia social, que parte de la existencia de propiedad privada, mercancía, intercambio, dinero, abstrayéndose de los procesos históricos que le dan lugar.

La deficiencia del método de la economía política y la diferencia con el materialismo dialéctico consiste en que para aquella, sus categorías de análisis no son explicadas por medio de las relaciones sociales en las que surgen y se mueven, sino por sí solas y con propiedades sustraídas a su contexto. Esta descontextualización se extiende a campos del conocimiento como el neodarwinismo ortodoxo, el cual se basa en los supuestos fundamentales de la visión cartesiana y exhibe un carácter reduccionista. Consiste en lo que Robert M. Young (1981) llama una "naturalización de sistemas de valores", es decir, un partir de la afirmación de que tales características han sido puestas por la naturaleza y por ello son incambiables por medio de la acción humana; el sujeto cognoscente del mundo sólo aspira a develar lo que ante él se presenta, lo que es "natural", sin que pueda jugar un papel activo en la elaboración del conocimiento, haciendo una escisión sujeto-objeto, o mente-realidad externa. Así los sistemas de valores, las prácticas y principios que regulan la acción humana parecen ser tan naturales como los objetos mismos de estudio.

Se desarrolla una línea de investigación científica basada en la comprensión de las esencias, desdeñosa del entendimiento de las relaciones, de los contextos espacio-temporales en los que se ubican los análisis, donde la aspiración es a una omnicomprensión basada en realidades y categorías mistificadas. Es por ello una ciencia fetichizada. Contra esta ciencia se desarrolla otra que pone el acento en las relaciones, fundamentada en la transitoriedad y modificación permanente de todas las formas de organización de la materia. Así tenemos que en su crítica del paradigma cartesiano en la biología, Richard Lewontin afirma:

El programa reduccionista explica las propiedades de los colectivos por medio de las propiedades de individuos ensamblados. La sociedad es una colección de individuos causalmente soberanos y las especies son la consecuencia de la supervivencia y la reproducción de organismos individuales. Pero el apetito del reduccionismo es insaciable. El organismo individual es sólo una parada temporal en el ineluctable proceso de atomización. Los mismos individuos deben ser explicables por medio de proteínas y enzimas, las cuales, a su vez, son producto de genes, los cuales son producto de la combinación de átomos (Lewontin 1991, p. XVI).

Lewontin señala, de acuerdo con Marx, que en las visiones reduccionistas del mundo vivo, los fenómenos se explican, justo por causa de propiedades inherentes a las partículas esenciales y no por las relaciones existentes entre el conjunto de los elementos en el contexto en el que se estudian. La partícula esencial impone sus características a las demás. Esta es una forma más de fetichismo. 
En biología evolutiva esta discusión tiene una gran relevancia. Uno de los procesos de la biología que más proclive ha sido para ser fetichizado es el de la herencia. La genética, desde tiempos de Gregor Mendel, ha explicado los procesos de transmisión de información a lo largo de las generaciones por causa de la existencia de partículas encapsuladas y conteniendo información codificada, la cual puede convertirse en tal o cual característica fenotípica. Esto es una proyección de los principios de las explicaciones preformistas del siglo XVIII. La biología molecular lleva este modelo a sus últimas consecuencias, por medio de la noción de gen y el mecanismo de transmisión contenido en el dogma central de la biología molecular (de ahora en adelante DCBM) (Crick 1970). De acuerdo con él, la información genética es un flujo que va siempre del DNA hacia el RNA y a la proteína, y además del DNA al propio DNA, en un proceso de auto-replicación.

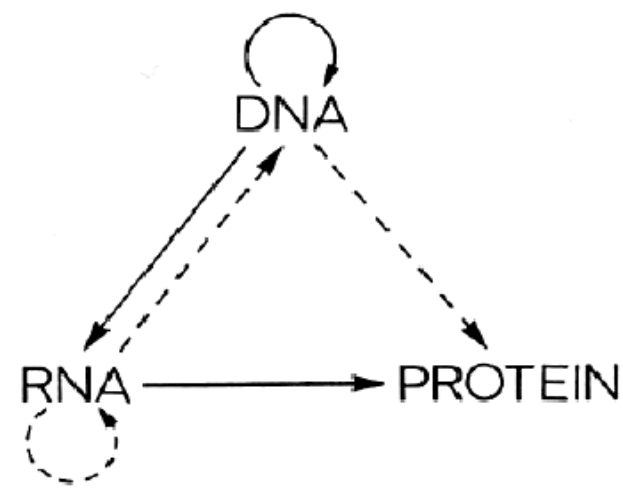

Figura 1: el dogma central de la Biología Molecular (Crick 1970).

Aquí se muestra un claro proceso de fetichismo, el cual ocurre a dos niveles: primeramente el proceso completo de trasmisión DNA-RNA-proteína, se aisla del conjunto de los procesos que ocurren en los demás niveles del mundo vivo, desde el subcelular hasta el ecosistémico, como si los ácidos nucleicos pudieran prescindir de todos ellos y más bien como si todos se derivaran de los ácidos nucleicos. En un segundo nivel el fetichismo expresa una forma análoga a la descrita por Marx en el análisis del movimiento del dinero en la esfera del interés. Así como en ésta el dinero parece surgir de sí mismo, en el modelo genocéntrico de Francis Crick, el DNA puede separarse del resto del proceso de transmisión; puede prescindir de transmitir información tanto para el RNA como para la proteína; en cambio, la genera para sí misma, se auto-informa. Este comportamiento, presentado de la manera como en el DCBM lo hace, presenta un proceso comandado por una molécula que da la impresión de "vivir" por sí misma. Una molécula de jerarquía superior porque no depende de ninguna otra para su existencia. En todo esto quedan ocultas las complejas relaciones que hacen al mundo de los organismos y a su evolución. Una vez más, la partícula esencial ya no tiene necesidad más que de sí misma para explicarse.

Sin embargo, el DCBM parte de una base falsa: Los ácidos nucleicos por sí solos no hacen nada, pero con el afán de encontrar una partícula esencial a la cual atribuir las propiedades de los seres vivientes y su evolución, se efectúa un torcido proceso epistemológico: Se observan las propiedades transmisoras de información de un tipo de molécula: el ácido nucleico; como lo que se busca es encontrar la molécula esencial, entonces ficticiamente se decide que las propiedades de esa molécula maestra se expresan por sí solas; se construye un modelo para explicar esta ficción y una vez construido, se proceden a hacer pruebas experimentales para mostrar lo que ya se sabía que ocurre, que los postulados del modelo se cumplen. Como los ácidos nucleicos en efecto, se replican, se concluye que lo hacen en función de sí mismos, que la experiencia lo ha mostrado. Pero no hay la percepción de que para postular tal principio, se ha simulado el movimiento propio del ácido nucleico presentándolo como auto-replicable. Este último punto, para explicarlo en términos de Imre Lakatos (1993, pp. 6572), no es otra cosa que una decisión de la comunidad científica que trabaja con ese concepto, y que hace infalsable al núcleo de su programa de investigación. 


\section{Teoría de Sistemas en Desarrollo y Operaciones Dialécticas}

Muchas de las opiniones contemporáneas contrarias al reduccionismo en teoría de la evolución son bien conocidas: Lewontin (1983, 2000, 2001), Richard Levins (2007), Michael R. Rose (1997), Dupré (1996), Lynn Margulis (2003), Eva Jablonka y Marion L. Lamb (2006), Snait B. Gissis y Jablonka (2011). Más centrados en el problema del concepto de gen y en el DCBM podemos citar a Karola Stotz (2006), Eugene V. Koonin (2012), Koonin y Yuri I. Wolf (2009), James A. Shapiro (2009), Charbel N. El Hani (2007), Leyla M. Joaquim y El-Hani (2010), El-Hani y Diogo Meyer (2013) y Jose DávilaVelderrain y Elena R. Álvarez-Buylla (2015), entre otros. Los análisis críticos que realizan desde diferentes ángulos al reduccionismo detrás del concepto ortodoxo de gen y al DCBM, indican una creciente ruptura con las nociones y metodologías que parecían definitivas para conocer el fenómeno de la herencia y los procesos de la evolución, y que hoy se encuentran asediados.

El Hani (2007), Joaquim y El-Hani (2010) y El-Hani y Meyer (2013), hacen completos resúmenes de los hallazgos que invalidan el concepto tradicional de gen y por tanto el DCBM, que lo tienen en un estado de crisis. Shapiro (2009) expresa que no existe un flujo unidireccional de información; que el DCMB, basado en una concepción atomista fragmentadora del mundo, es insostenible junto con ésta, lo mismo que su carácter determinista y que las células poseen el control de las funciones celulares mediante procesos informáticos más que mecánicos (como los postulados por el DCBM). Más dentro de las reflexiones sobre teoría de la evolución, Koonin (2012) rechaza la validez del DCBM como principio universal, analizando el papel de la transferencia de información proteína-ácido nucleico, por parte de los priones. En compañía de Wolf, Koonin (2009), deriva de sus críticas al DCBM una pluralidad epistémica para entender la evolución: ésta es tanto darwiniana como lamarckiana, dependiendo de qué procesos y casos se analicen.

A esta lista habrá que agregar a Susan Oyama y su Teoría de Sistemas en Desarrollo (DST). Esta teoría, de acuerdo con la misma autora, "concibe al desarrollo y la evolución como procesos de construcción y reconstrucción en los cuales los recursos heterogéneos están rearreglados contingente pero más o menos fiablemente para cada ciclo de vida" (Oyama 2001, p. 1).

Oyama se posiciona contra del genocentrismo y el determinismo del neodarwinismo. Su método es susceptible de ser analizado en compatibilidad con el método dialéctico de Marx y Engels y con su antecedente en Hegel. Postulo que la DST contribuye a liberar a la biología de las cadenas de los fetichismos de la linearidad y unidireccionalidad genocéntricas. El carácter dialéctico de la DST se manifiesta cuando Oyama deja ver que la evolución sólo se entiende por medio de relaciones y unidad entre elementos opuestos.

Cada clase de factor [de la evolución] es frecuentemente efectivo sólo a través del otro. Los genes influencian el desarrollo alterando el medio inmediato para varios constituyentes del organismo, mientras el ambiente frecuentemente ejerce influencia sobre la tasa y el temporalidad de la transcripción genética (Oyama 2000, p. 37).

Lo cual es una aplicación de la tesis hegeliana de la relación causa-efecto. No existe una sin la otra. Los genes ejercen una influencia sobre el ambiente precisamente debido a que éste existe en tanto ente concreto y determinado, con funciones específicas e interactivas sobre los genes, entre otros entes del organismo. Es indispensable para que estos puedan trabajar, no existen genes ni organismo sin ambiente (Lewontin 2000).

\subsection{Cuestionamiento de la transmisión lineal}

Oyama se pronuncia contra una concepción "transmisionista" para comprender el carácter de los organismos y su evolución. Afirma: "Los cuerpos y las mentes son construidos, no transmitidos. Aun lo que es descrito de manera general como transmitido culturalmente, no es simplemente transferido en bloque, de un ser a otro" (Oyama 2000, p. 29).

No se transmiten características aisladas o programas, sino "medios" para el desarrollo. Entre ellos, desde luego, se encuentran los genes, pero otros elementos como el sistema reproductivo materno, el 
cuidado parental, y el conjunto de las relaciones con los elementos bióticos y abióticos (Oyama 2000, p. 29).

La naturaleza no es transmitida sino construida. La naturaleza de un organismo -es decir, las características que lo definen en un momento específico- no es genotípica sino fenotípica. En vista de que los fenotipos cambian, las naturalezas no son estáticas sino transicionales y en vista de que cada genotipo tiene una norma de reacción, puede dar lugar a múltiples naturalezas (Oyama 2000, p. 48).

En esta descripción está presente la idea del proceso evolutivo como Devenir. La naturaleza es construida por medio de distintos procesos. La transmisión genética es uno de ellos, pero no necesariamente el más importante siempre. Ocurre dentro del proceso de la construcción. No tiene un papel por fuera de ésta porque no hay transmisión sin un destinatario fuera del transmisor ¿A qué o quién se transmite nada si no se cumple esta condición? Transmisor y destinatario, emisor y receptor tienen una existencia simultánea y codependiente. Entender la existencia y función de un transmisor como el DNA en ausencia de las moléculas o entidades a las que se ha de transmitir la información, significaría hacer una "sobrenaturalización" de ella, o dicho de otro modo, un proceso de diseño de un tipo de molécula (el DNA) llevado a cabo previamente a lo que tendría que estar presente para que la función de tal molécula se cumpliera, lo cual es un sinsentido. La función de transmisor del DNA existe sólo cuando se presentan los péptidos que han de acoplarse a las porciones de aquel para ir ensamblando las cadenas polipeptídicas y las proteínas, la cuales a su vez no tienen sentido sin insertarse en el conjunto de vías metabólicas. Todo ello evoluciona conjuntamente. Lo mismo es válido en sentido opuesto: no existe destinatario si no hay transmisor. No tiene caso imaginar ni postular la existencia de péptidos sin la presencia de la molécula que cumple la función de ensamblarlos y convertirlos en proteínas. Ninguna de las dos partes preexiste a la otra. Se trata de un vínculo inescindible y como toda relación de un sistema complejo, es bi o multi direccional. Cualquier transmisión de información implica la existencia de un receptor, lo que significa que hay un proceso de co-construcción de uno y el otro.

El carácter fetichista del DCBM consiste en que, al postular que el DNA es capaz de auto-replicarse y representarlo como un proceso independiente de los demás, asevera que preexiste al potencial receptor de su información, o como si éste se hubiera originado y evolucionado para adaptarse a la existencia, estructura y "función" del transmisor, como si el carácter de transmisor estuviera ya fijado con anterioridad a su existencia y destinado a cumplir su función antes de cualquier posibilidad de transmisión. Todo esto, lógica y ontológicamente, carece de coherencia.

La idea de la existencia de un transmisor que se auto-transmite, como el DNA en el dogma central es la idea de un ser en estado de pureza, condición característica del fetichismo, y con ello es manifestación del ser indeterminado, abstracto. Esto nos remite a las reflexiones de Georg W.F. Hegel acerca del Ser puro como inmediato, indeterminado, abstracto:

El Ser puro -sin ninguna determinación-. En su inmediatez indeterminada es similar sólo a sí mismo y no diferente a ningún otro; no contiene diferenciaciones ya sea dentro de sí ni en relación con algo externo [...]. Es pura indeterminabilidad y vacuidad. Nada se puede intuir en él [...]. De hecho la inmediatez del Ser indeterminado es Nada, ni más ni menos (Hegel [1812-1816]1951, p. 94).

Este Ser puro, que en su pureza, o ausencia de relaciones no contiene propiedades, no puede ser tomado como referencia. Para que ésta exista es necesario que se abandone el estado de indeterminación para determinarse, para adquirir concreciones, lo cual implica relaciones. "Un Ser determinado o finito es el que se refiere a otro" (Hegel [1812-1816]1951, p. 98) porque justo por Ser determinado, posee un contenido, que sólo adquiere sentido en la relación con su otredad, siendo la relación la que dota al Ser de sus determinaciones concretas.

Ningún proceso en el universo puede comenzar a partir del Ser indeterminado, el cual carece de posibilidades de ser transformado en otro ser (Hegel [1812-1816] 1951, p. 107). Este es un asunto que el DCBM no parece comprender. La determinación, al implicar relación, es la que establece la situación del Ser, el Ser de propiedades, tiempos, transiciones, dependencias externas e internas, es decir, con otros Seres determinados, aunque nunca igualmente determinados, pues en ese caso la 
determinación se disolvería y todo se convertiría en un solo Ser: indeterminado y abstracto, lo cual es la auto-anulación del movimiento. El Ser indeterminado es el Inicio, pero en su indeterminación, se despoja de movimiento y de Devenir, de relaciones y referentes.

La DST expresa estos principios ontológicos dialécticos. El desarrollo, como opuesto a la concepción "transmisionista" no es acreción o despliegue de lo ya existente, no es simple aumento de tamaño. Es la explotación o aprovechamiento de las posibilidades en un cierto estado de la relación organismo-ambiente, más allá de lo contenido en códigos, es la emergencia de nuevas categorías ontológicas, de nuevas determinaciones y mediaciones, originadas en los procesos relacionales organismo/ambiente y genotipo/fenotipo, profundamente imbricados.

Para Oyama, el fenotipo es una categoría central en la medida en que constituye la síntesis de los elementos que intervienen en la construcción del organismo. En el fenotipo se integran los procesos de desarrollo, los resultados de la transmisión, la influencia de las interacciones del organismo con su ambiente y la actividad toda de aquel. El fenotipo es, en términos dialécticos, un estar-dejando-de-ser para estar-llegando-a ser; es un "aún no" que significa el abandono de un estadio previo pero que no llega a un fin último dado que nunca se parte de un estado fijo para llegar a una meta prefijada o final.

\subsection{Negación de binariedades fijas}

Consecuentemente con lo anterior, Oyama se pronuncia contra la separación entre lo "innato" y lo "aprendido" y con ello entre lo llamado "natural" y lo producido por la crianza. Para ella ambos elementos forman un solo proceso complejo que es el desarrollo:

La crianza (las interacciones del desarrollo a todos los niveles) es tan crucial a los caracteres típicos como para los atípicos, tan formadora de caracteres universales como de los variables, tan básica para los caracteres estables como para los lábiles (Oyama 2000, p. 48).

La naturaleza es más bien, el producto de los procesos que son las interacciones del desarrollo que llamamos crianza. Al mismo tiempo, la naturaleza fenotípica es un recurso del desarrollo para interacciones subsecuentes [...]. Identificar la naturaleza con el genoma es perder la historia total del desarrollo en el mismo sentido en que los preformistas lo han venido haciendo (Oyama 2000, pp. 4849).

La biología evolutiva neodarwinista y genocéntrica, basa su metodología en la existencia de distintas binariedades, mutuamente excluyentes: naturaleza/crianza, organismo/ambiente, genotipo/fenotipo, masculino/femenino.

Característico de estas binariedades es que están compuestas por elementos claramente separados e identificados, su existencia está escindida de la de su contraparte. Se sostiene también que esta separación y diferenciación es fija y permanente. Al igual que su estabilidad. De esta manera, no hay posibilidad de comprender la evolución de otras categorías integradoras. Oyama rechaza la obligatoriedad de usarlas como referente o marco teórico para entender la evolución; con ello flexibiliza y dinamiza le teoría de la evolución; la libera de ataduras a categorías fijas, estables y excluyentes. Busca la integración en síntesis dinámicas cualitativamente distintas a las de las binariedades mencionadas:

El concepto de sistemas evolutivos de desarrollo nos da una visión unificada del desarrollo integrándolo con la evolución. Esta dualidad ya no se requiere más. La distinción heredado-adquirido, en la medida en que se construye como una distinción entre clases de procesos en desarrollo o fuentes de forma, puede ser eliminada - no modificada o convertida en una cuestión de grados, sino eliminada (Oyama 2000, p. 71).

Sólo pensando a los genes y al ambiente como fuentes alternativas de formas fenotípicas es como adquiere sentido la oposición entre factores genéticos y ambientales (Oyama 2002, p. 179). Para Oyama no son alternativas ni excluyentes, sino integradas en un sistema de transiciones cuantitativocualitativas. 
Más que ser guiados por una estrategia dominante de identificación de los componentes innatos o de separar la varianza determinada por los elementos genéticos y ambientales [...] podemos razonablemente enfocarnos en la interacciones y las relaciones mismas (Oyama 2000, p. 48).

Al remarcar la importancia del desarrollo como proceso de integración de los elementos que conforman a los seres vivos, se debilita la explicación monista o esencialista de los códigos informacionales y los mecanismos de su transmisión. No es posible encontrarle significado a unos y otros si no es en función de un contexto ambiental, externo, no enajenado de ni subordinado a las unidades genéticas, pero formando una unidad de opuestos. La información genotípica por sí misma carece de sentido si no es traducible a un fenotipo, pero no preexiste a él, es simultáneamente construido.

También resulta debilitada la concepción pan-adaptacionista. La continuidad de una especie no es el resultado siempre de actos de adaptación al medio, sino de una construcción que ocurre en las distintas condiciones ambientales en las que los organismos se encuentran y condicionadas por los procesos de regulación a este respecto. Stotz (2006) señala que las secuencias de DNA se pueden revolver, modificar y ser creadas en los procesos post transcripcionales y exhibe a manera en como en la realidad las secuencias literales de los códigos son amplificadas en y por los procesos de regulación y epigénesis, no son sólo copiadas. No sólo es la multiplicidad de las variables lo que cuenta, sino los resultados distintos a los que llega en condiciones moleculares, climáticas y ecológicas concretas. Tal es el caso de la metilación del DNA, en el que grupos metilo adheridos a las citosinas del DNA, silencian la expresión de los genes a los que se adhieren, dando lugar a procesos de plasticidad fenotípica sin la alterar la secuencia de nucleótidos del DNA (Jablonka \& Lamb 2005, pp. 128-131).

La relación causa / efecto es otra de las escisiones que son moneda corriente en la ciencia reduccionista incluyendo. De acuerdo con esto, la información genética precede a toda formación fenotípica y es la causa posterior de la segunda, su efecto. Oyama no acepta esta escisión. La causa no es tal si no se refiere simultáneamente al efecto y ambos son co-construidos también. Pensar que la causa es independiente al efecto es pensar, en el caso de la molécula esencial, el DNA y el genotipo preexistiendo al fenotipo. Oyama observa:

Lo que [el empirismo y el nativismo] comparten es la creencia de que la información puede preexistir al proceso al que da lugar. Pero la información "en los genes" o en el ambiente no es biológicamente relevante hasta que participa en los procesos fenotípicos. Deviene en algo significativo en los organismos sólo en la medida en que se construye como "información" por medio de su sistema en desarrollo (Oyama 2002, pp. 15-16)

Se distingue una operación dialéctica en esta apreciación, la cual va dirigida contra el fetichismo genocentrista. La concepción fetichista del mundo necesita de las "preexistencias" para desarrollarse. Aquello que preexiste es el fetiche mismo porque es lo que se muestra como prescindiendo de relaciones, como se ha explicado ya. Es entendida como causa universal o última. Las preexistencias se manifiestan como las misteriosas propiedades "inherentes" y "esenciales". El fetiche, en la medida en que así se conciba, es lo "puesto por la naturaleza". Pero si lo que se concibe es un proceso en el que las circunstancias específicas de la existencia de un genoma solamente cumplen con su papel en la medida en que intervengan en procesos fenotípicos y requieran de la presencia de los fenotipos, entonces la preexistencia es lo que carece de sentido, y es posible dejar el fetichismo del gen a un lado.

\subsection{La imbricación de los opuestos}

Otra operación dialéctica importante es la que Oyama usa con su concepto de "interacción constructivista":

Reemplazo la visión convencional de la “interacción” entre organismos y ambientes separados e independientes por el término "interacción constructivista" [...]. En la interacción constructivista los organismos y su ambiente definen los aspectos relevantes de cada uno, y que pueden afectarse mutuamente. Esto es lo que otros como por ejemplo, Lewontin [...] llama “interpenetración" de organismo y ambiente (Oyama 2000, p. 3). 
Cuando la interacción constructivista es observada como fundamentalmente importante para la formación [...] de todos los rasgos [...], entonces el papel del ambiente no es complementario al de la biología, sino constitutivo de él en el mismo modo en que los genes lo son (Oyama 2000, p. 63).

Se va más allá de la concepción de las relaciones entre organismos y de organismos con el ambiente entendidas como "interacciones". En éstas el vínculo que se da es algo que puede ser casual o permanente y entre entidades claramente diferenciadas y estables, independientes entre sí. La interacción les permite mantenerse, entrar en contacto con lo que es externo a ellas para conservar la identidad. La propuesta interaccionista presenta con frecuencia a los elementos interactuantes, relacionándose de manera fija, constante y con trayectorias y direcciones que parecen establecidas de inicio.

La interpenetración dialéctica asume que las relaciones se dan entre elementos considerados como opuestos, pero cuya oposición es activa, relativa y transitoria. La actividad no es simplemente "intercambio" de materia y energía o de información, sino transformación de su medio y con ello transformación de sí mismo, de su propia naturaleza. En la interpenetración establecida entre dos cuerpos o entidades, se supera la interacción de lo estable y fijo. En cambio, se expresa como una relación en la que se dan tanto la identidad como la negación y auto-negación (Levins 2007). La interpenetración asume que dos entes relacionados son distintos por principio, pero por principio también, se explican por la identidad que se establece en cada uno de ellos. La identidad propia es la negación de la del Otro y del Otro como tal; la negación del Otro no se produce, empero, como simple exclusión de la identidad del primer elemento, juzgado en estado simple y estacionario. En vez de ello, es la actividad y el devenir propios de ese Ser, la que produce la negación del Otro y entonces la negación ya se entiende como relación. Hegel explica:

De acuerdo con la manera de su Devenir, el Ser Determinado en general es el Ser, junto con un No-Ser, de manera tal que este último es retomado en una simple unidad con el Ser. Es en el No-ser cuando es retomado dentro del Ser [...] que el todo concreto está en la forma del Ser (Hegel [1812-1816]1951, p. 122).

El todo concreto es la unidad del Ser y No-Ser en su Devenir, o más precisamente como momentos específicos del Devenir. Es la unidad de un Ser determinado con su negación, es el Devenir, el movimiento y actividad lo que produce esta unidad de elementos opuestos. Como cada negación que surge de ese Devenir, de ese movimiento pendular entre Ser y No-ser, implica actividad; se desprende que cada entidad auto-identificada consigo misma, se autoniega en su actividad, pues ésta es transformadora de sí misma y en esa medida, transformadora de su otredad. Se trata de un proceso en el que todo ente sólo se puede explicar en función de aquellos que lo niegan, pero en donde esa negación es su propio Devenir y deviene en una autoafirmación. Me afirmo como negación de los demás y como proceso de auto-negación al reflejarme en los entes con los que me relaciono. La forma específica de mi auto-afirmación y auto-negación es la afirmación y negación de mi otredad, es resultado de las determinaciones concretas que en cada momento del Devenir poseo y poseen los Otros distintos a mí. Al estar interpenetrado, estoy contenido y al mismo tiempo diferenciado en mi opuesto, en ese Otro que no es yo pero que es yo. Lo contengo y me contiene. Las formas específicas de interpenetración y de comportamiento de los elementos interpenetrados, es distinta en cada contexto, tiene un carácter provisional y transitorio.

La propuesta de Oyama se dirige a la flexibilización y dinamización de las binariedades señaladas en el apartado anterior. En la "interacción constructivista", la fijeza de las entidades de la binariedad también deja de existir y se ubican una frente a la otra como opuestos dinamizados, como entidades cuya distinción no se comprende si no es en función de su estar embebidas en la Otra.

Cuando la interacción constructiva es observada siendo fundamentalmente importante para la formación [...] de todas las características, incluyendo las 'biológicas', entonces el papel del ambiente no es complementario al de la biología, sino constitutivo de él de la misma manera en que los genes lo son (Oyama 2000, p 63). 
La codificación genética, así, no debe ser entendida como separada de las características conocidas como "adquiridas". Una y otra forman esos sistemas funcionales en desarrollo en los que el genoma está inmerso en el ambiente, en las relaciones ecológicas. Se trata pues, de procesos en los que temporalidad, funcionalidad y espacialidad se encuentran integrados.

Organismo y ambiente, innato y adquirido, genético y ambiental forman una totalidad dialéctica. Su binariedad se disuelve y auto-niega mediante su actividad interna, que es proyección externa. Así como no hay transmisor sin destinatario ni causa sin efecto, tampoco existe lo innato sin lo adquirido, pues el organismo es la relación con el ambiente. La construcción de los ambientes deja de ser operación mecánica siempre dirigida por replicadores.

El concepto de sistemas de desarrollo evolutivo proporciona una visión unificada del desarrollo desde el momento en que lo integra con la evolución. El dualismo no es requerido más, la distinción heredadoadquirido, en la medida en que es construida como una distinción entre clases del proceso de desarrollo o de las fuentes de la forma, pueden ser eliminados - no modificados o convertidos en un asunto de grados, sino eliminados (Oyama 2000, p 71).

La herencia y la crianza se producen recíprocamente dando lugar a un sistema cuyo análisis no es más el de una u otra categoría ni siquiera en su acepción de interacción mecánica, sino a la síntesis de ambas, a su eliminación en un modelo cualitativamente diferente. Si bien los elementos que la integran pueden permanecer distinguibles, su expresión como interacción constructivista o interpenetración las diluye.

De aquí es posible remitirnos al concepto hegeliano-marxiano de Aufhebung, e intentar hacer una aplicación del mismo. Como hemos mencionado, dos elementos opuestos en un contexto específico de relaciones no pueden existir si no es en función de su opuesto. Esto aparece, en palabras de Marx, como "recíprocamente indispensables", aunque tengan una existencia autónoma, "permaneciendo [...] externos entre sí" (Marx [1857-1858]1987, p. 13) y en su devenir como opuestos, llegan a originar situaciones específicas dadas por sus oposiciones, síntesis cualitativamente distintas a las de sus predecesores, pero inexplicables sin la relación entre ellos. Cuando Marx analiza las relaciones entre la producción y el consumo en la sociedad, logra explicar ese proceso elocuentemente:

La producción es también inmediatamente consumo. Doble consumo subjetivo y objetivo: el individuo que al productor desarrolla sus capacidades, las gasta también, las consume en el acto de la producción exactamente como la reproducción natural es un consumo de fuerzas vitales [...]. Igualmente, el consumo es de manera inmediata producción, del mismo modo que en la naturaleza el consumo de los elementos y de las sustancias químicas es producción de plantas (Marx [1857-1858]1987, vol. 1, pp. 10. 11).

En consecuencia la producción es inmediatamente consumo, el consumo es inmediatamente producción. Cada uno es inmediatamente su opuesto. Pero al mismo tiempo tiene lugar un movimiento mediador entre los dos. La producción es mediadora del consumo [...]. Pero el consumo es mediador de la producción en cuanto crea para los productos el sujeto para el cual ellos son productos (Marx [18571858]1987, p. 11).

\section{La producción}

no solamente produce un objeto para el sujeto sino también un sujeto para el objeto. La producción produce, pues el consumo 1) creando al material de éste; 2) determinando el modo de consumo; 3) provocando en el consumidor la necesidad de productos que ella ha creado originariamente como objetos (Marx [1857-1858]1987, pp. 12-13).

Ambos extremos de este proceso son claramente diferenciables, pero ello no oculta su interdependencia ni su estar afirmado en el contrario. Marx agrega una propuesta metodológica y conceptual general: "Cada uno de los términos no se limita a ser el otro de manera inmediata y tampoco el mediador del otro, sino que, realizándose, crea al otro y se crea en cuanto otro" (Marx [1857-1858]1987, vol. 1, p. 13). Es decir, ambos términos se producen mutuamente mediante la actividad, no de manera espontánea ni mecánica. No son resultado de un automatismo, sino de la autoconciencia de los productores. 
El concepto de interpenetración o interacción constructivista, expresa el proceso expuesto por Marx. Lo que Marx menciona es que cada uno de los elementos de la relación está presente ya desde el momento en que el opuesto está presente. La proyección de la producción hacia el consumo está ya construida en el proceso de la producción. Este es un acto de consumo pues implica por una parte los gastos de energía del trabajador, o de energía del medio, así como de materia prima. Por el otro es ya el acto de consumo del producto final pues está en la mente del productor un plan dirigido al proceso del consumo.

Aplicando este método a la biología, observaremos que existe una notable diferencia por cuanto que en los procesos biológicos no es posible hablar de una premeditación ni de una auto-conciencia de los pasos, finalidades, objetivos del proceso por parte del sujeto del proceso productivo. Pero ello no significa la ausencia de actividad. La actividad no es exclusivamente lo que se hace de manera autoconsciente y premeditada, es todo proceso conducente a una transformación del medio en el que el sujeto de la actividad se encuentra, al tiempo que se transforma la naturaleza misma de éste. La producción de un sujeto para el objeto y viceversa se expresan en la naturaleza como un enroque constante entre el organismo y el ambiente. Más aun, es un comportamiento dual objeto-sujeto tanto del organismo como del ambiente. No es la unidireccionalidad postulada por el pan adaptacionismo, según el cual el organismo se limita a ser un objeto pasivo-contemplativo de cambios en el ambiente ajenos a él, sino el sujeto de transformación de sí mismo y con ello del ambiente (Lewontin 2001).

Cuando lo "genético" se concibe separado de lo "aprendido", se desestructura el proceso relacional que integra a esos dos elementos de la construcción de los sistemas vivos, se reifica y parcializa el sistema. No se piensa en sus componentes como reflejo y realización de su otredad. Pero lo heredado no tiene sentido si no es en función de un sistema de desarrollo, ambos coexisten como uno para el otro, no como un en sí. El mecanicismo, como reduccionismo que es, se queda en la percepción de ambos procesos como escindibles, y no los comprende integralmente, su interdependencia le pasa inadvertida. En la DST, en cambio, se comprende que el objeto de la evolución es simultáneamente sujeto de ella, en la que el objeto productor del sujeto, es inmediatamente el sujeto, está contenido en él, no es únicamente receptor de información. La herencia produce sujetos de y para el objeto transmisor y en la transmisión va contenida la construcción del objeto que la posibilita, y que deviene en sujeto. Pero como no solamente existe la herencia, sino el ambiente, entonces se efectúa ese proceso de co-construcción de uno y el otro. El proceso comprende los componentes heredables y aprendidos como sujetos para sí, objetos para el sujeto y sujetos para el objeto. El proceso evolutivo es la síntesis de la dualidad herencia/crianza como interpenetraciones; estas dos categorías y los elementos de la dualidad se desvanecen en la nueva explicación, a favor de un sistema de relaciones distinto al de sus componentes previos.

Un sistema en desarrollo integra en un nivel distinto lo heredado y lo aprendido, negando a ambos, no es una mezcla ecléctica. Es el Aufhebung en la teoría contemporánea de la evolución.

\section{Conclusión}

El modelo de la DST propuesto por Susan Oyama, al aproximarse a, e incorporar, varios elementos importantes de la dialéctica, es una importante contribución para modificar de raíz la concepción fetichista de genes y ácidos nucleicos. Esta aportación tiene y puede tener un alcance que vaya más allá de las apreciaciones evolucionistas como algo cerrado, interno, centrado en los sistemas de transmisión genética. Puede adquirir un alcance mayor en el que queden al descubierto las entretelas ideológicas del darwinismo vulgar y su participación en una visión falsa e ilusoria del mundo, todo a fin de transformar las concepciones que sobre el mundo vivo y social se tienen; transformar a éste y no contentarse con la mera "comprensión" pasiva o contemplativa.

En este sentido, queda a debate si la propuesta analizada puede considerarse que está contribuyendo a producir una revolución en la biología evolutiva (Kuhn 1969); si la situación del paradigma neodarwinista (si es que aceptamos llamarlo así) es una de crisis, de la cual pueda salir un 
nuevo paradigma o si éste y su rival pueden permanecer coexistiendo de manera más o menos autónoma. Hay que tomar en cuenta que Kuhn analizó los casos de la física y la química para construir su modelo. La historia de la biología es distinta. En ésta se ha mostrado que una concepción teórica puede coexistir con otras por largos períodos, aun cuando parezca que alguna parezca desacreditada (por ejemplo, el Lamarckismo). También se muestra que la discusión sobre epigénesis contra preformismo, de mecanicismo contra holismo, de esencialismo contra relacionismo, han estado presentes desde hace siglos en biología, sin que globalmente ninguna se haya visto seriamente dañada al nivel, por ejemplo, de la teoría del éter en física.

Esto no significa que todas las propuestas teóricas en biología estén al mismo nivel en cuanto a su valor de verdad ni que todas están deficientemente construidas. Todas las corrientes de pensamiento, aun las más vulgares dentro de la biología evolutiva, han aportado importantes conocimientos sobre la materia y la naturaleza del mundo vivo y generado debates trascendentales. Es la elevada complejidad de los sistemas de estudio en biología lo que hace que el camino a la verdad sea algo tortuoso y entreverado, mucho más que en la física clásica o la química.

Pero es precisamente por esto último por lo que se puede pensar que las teorías biológicas que ponen el acento en la complejidad son las que pueden resolver mejor los problemas a los que se enfrenta el conjunto de la ciencia biológica. La obra de Oyama se ubica dentro de esta amplia corriente.

Afirmo que la DST es comprensible por medio de la dialéctica; en ella están contenidos muchos de los principios del conocimiento dialéctico del mundo, presentes desde la obra de Hegel y de la dupla Marx-Engels, y que se constituye como una teoría que muestra las posibilidades para superar muchas de las deficiencias del neodarwinismo, limitado por su obsesión monista y unilineal de la evolución e incapacitado para comprender la pluralidad y complejidad de los procesos evolutivos. La DST supera los fetichismos que están presentes en la biología por medio de un método de ruptura con la costumbre de explicar al mundo como entes parcelados y mutuamente excluyentes.

Es esa ruptura con el fetichismo, que científicos como Oyama protagonizan, lo que está ayudando a construir un amplio campo dentro del programa evolucionista, que rescata los elementos más avanzados tanto del darwinismo como del Lamarckismo y sus respectivas afinidades a fin de hacerla más eficaz para acometer los retos a los que este se enfrenta hoy en día.

Bibliografía

Crick, F. (1970), "Central Dogma of Molecular Biology", Nature 227: 561-563.

Dávila-Velderrain, J. y E. Álvarez Buylla (2015), "Esquemas de causación lineales en biología posgenómica. La subliminal y conveniente suposición del mapeo uno a uno entre genotipo y fenotipo”, Interdisciplina 3(5): 61-77.

Descartes, R. ([1647]1995), Los principios de la filosofia, Madrid: Alianza Universidad.

Dupré, J. (1996), The Disorder of Things: Metaphysical Foundations of the Disunity of Science, Cambridge, MA: Harvard University Press.

Eagleton, T. (1996), Ideology, London: Longman

El-Hani, C.N. (2007), "Between the Cross and the Sword: The Crisis of the Gene Concept", Genetics and Molecular Biology 30(2): 297-307.

El-Hani, C.N. y D. Meyer (2013), "The Concept of Gene in the Twenty-first Century. What are the Open Avenues?", Contrastes. Suplemento 18: 55-67.

Engels, F. ([1893]1997), “Carta a Franz Mehring, 14 de julio de 1893”, en Moore, S. (ed.), Crítica de la democracia capitalista, México: Siglo XXI.

Gissis, S.B. y E. Janlonka (eds,) (2011), Transformations of Lamarckism: From Subtle Fluids to Molecular Biology, Cambridge, MA: MIT Press. 
Hegel, G.W.F ([1812-1816]1951), Science of Logic, London: George Allen \& Unwin Ltd.

Jablonka, E. y M.J. Lamb (2006), Evolution in Four Dimensions: Genetic, Epigenetic, Behavioral and Symbolic Variation in the History of Life, Cambridge, MA: MIT Press.

Joaquim, L.M. y C.N. El-Hani (2010), “A Genética em Transformaçao: Crise e Revisao do Conceito de Gene”, Scientiae Studia 8(1): 93-128.

Koonin, E.V. (2012), “Does the Central Dogma Still Stand?”, Biology Direct 7:27.

Koonin, E.V. y Y.I. Wolf, (2009), “Is Evolution Darwinian or/and Lamarckian?”, Biology Direct 4:42.

Kuhn, T.S. (1969), La estructura de las revoluciones científicas, México: Fondo de Cultura Económica.

Lakatos, I. (1993), "La falsación y la metodología de los programas de investigación científica”, en Lakatos, I., La metodología de los programas de investigación científica, Madrid: Alianza Universidad. pp. 17-133.

Lenk, K. (2000), El Concepto de Ideología: Comentario Crítico y Selección de Textos, Buenos Aires: Amorrortu.

Levins, R (2007), “Dialectics and Systems Theory”, en Levins, R. y R.C. Lewontin (eds.), Biology under the Influence: Dialectical Essays on Ecology, Agriculture and Health, New York: Monthly Review Press, pp. 101-124.

Lewontin, R.C. (1983), “The Organism as Subject and Object of Evolution”, Scientia 118: 63-82. Reimpreso en Levins, R. y R.C. Lewontin (eds.) (1985), The Dialectical Biologist, Cambridge, MA: Harvard University Press, pp. 85-106.

Lewontin, R.C. (1991), "Foreword”, en Tauber, A.I. (ed.), Organism and the Origins of Self, Dordrecht: Kluwer, pp. XIIIXIX.

Lewontin, R.C. (2000), The Triple Helix: Gene Organism and Environment, Cambridge, MA: Harvard University Press.

Lewontin, R.CF. (2001), "Gene, Organism and Evironment”, en Oyama, S., Griffits, P.E. y R.D. Gray (eds.), Cycles of Contingency: Developmental Systems and Evolution, Cambridge, MA: MIT Press, pp. 59-66.

Margulis, L. (2003), Una revolución en la evolución, Valencia: Universitat de Valencia.

Marx, K. ([1857-1858]1987), Elementos Fundamentales para la Crítica del a Economía Política (Grundrisse), México: Siglo XXI.

Marx, K. ([1867]1988), El Capital, Tomo 1, México: Siglo XXI.

Marx, K. ([1894]1985), El Capital, Tomo 3, México: Siglo XXI.

Marx, K. y F. Engels ([1845]1953), L’Ideologie Allemade, París: A. Costes.

Oyama, S. (2000), Evolution's Eye: A Systems View of the Biology-Culture Divide, Durham: Duke University Press.

Oyama, S. (2001), "Introduction: What is Developmental Systems Theory?", en Oyama, S., Griffits, P.E. y R.D. Gray (eds.), Cycles of Contingency: Developmental Systems and Evolution, Cambridge, MA: MIT Press, pp. 1-11.

Oyama, S. (2002), The Ontogeny of Information: Developmental Systems and Evolution, Durham: Duke University Press.

Rose, S. (1997), Lifelines: Biology, Freedom. Determinism, London: Penguin.

Rubin, I. (1974), Ensayos sobre la teoría marxista del valor, México: Pasado y Presente.

Shapiro, J.A. (2009), "Revisiting the Central Dogma in the 21st Century”, Annals of the New York Academy of Sciences 1178: 6-28.

Stotz, K. (2006), "Molecular Epigenesis: Distributed Specificity as a Break in the Central Dogma", History and Philosophy of the Life Sciences 26(3-4): 527-544.

Young, R.M. (1981), “The Naturalization of Value Systems in the Human Sciences”, en Bartholomew, M., Norton, B. y R.M. Young, Science and Belief: from Darwin to Einstein', Block VI, Problems in the Biological and Human Sciences, Milton Keynes: Open University Press, pp. 63-110.

Zizek, S. (2003), Ideología: un mapa de la cuestión, México: Fondo de Cultura Económica. 